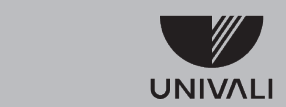

UNIVERSIDADE DO VALE DO ITAJAí

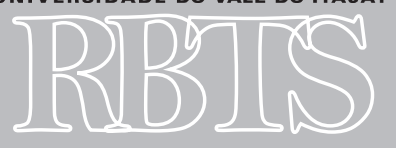

Revista Brasileira

de Tecnologias Sociais
1 Graduado em Direito pela Universidade do Vale do Itajaí. Aluno do Programa de Mestrado em Gestão de Políticas Públicas da Univali. E-mail: emidiocapistrano@hotmail.com.

\section{O MODELO BEHAVIORISTA DE POLÍTICAS PÚBLICAS: ENTRE A DEPENDÊNCIA E A INDEPENDÊNCIA}

\author{
Emídio Capistrano de Oliveira ${ }^{1}$
}

RESUMO: Este ensaio levanta um olhar sobre os referentes "história” e "behaviorismo". Política Pública em regra é tratada como dinâmica de formulação de agendas e operacionalização associada a problemas sociais, jurídicos, de recursos públicos ou expertise gerada por think thanks e daí por diante. Não obstante, a gênese que antecede estes modelos analíticos, e que os justifica como uma ideia de ciência, pouco ou nunca é exaurida. Contudo, são produtos de saberes científicos consumidos por governo e sociedade como sendo dados sempiternos. Mas são construções sociais que emergem geopoliticamente e em condições e situações específicas. Por este motivo um recuo ao movimento behaviorista norte-americano, que proveu e produziu as técnicas, e o ambiente para a emergência das políticas públicas. Perceber como este saber torna-se hegemônico e homogêneo como ciência é basilar para estabelecer um olhar sobre o modelo atual de políticas públicas. Para tanto o ensaio utilizará a metodologia historiográfica da escola dos Annales para historicizar e problematizar a formação das políticas públicas. O objetivo final será tecer até que ponto as políticas públicas como ciência conseguiu independência deste espaço cujas ideias se gestaram. Identificar rupturas e continuidades. Perceber consequências da retórica e teórica behaviorista advindas dessa mescla. É esse debate que o ensaio levanta. No entanto, considera-se ao final que sonegar o tema pode ser uma potência de dependência por desvelar submissões impertinentes que exigem a ilusão da manutenção de hegemonias e homogenias em uma ideia de ciência.

PALAVRAS-CHAVE: Políticas públicas; behaviorismo; ciência; policy analysis.

ABSTRAC: This essay raises examines the referents "history" and "public policies". Public policy is generally treated as a dynamic agenda of formulation and operationalization associated with social, legal, public resource or expertise issues generated by think thanks and the like. Nevertheless, the genesis that precedes these analytical models, and that justifies them as an idea of science, is seldom or never examined in detail. However, they are products of scientific knowledge consumed by government and society as eternal data. But they are social constructions that emerge geopolitically and under specific conditions and situations. For this reason, there was a going back to the North American behaviorist movement, which provided and produced the techniques, and the environment for the emergence of public policies. 
Perceiving how this knowledge became hegemonic and homogeneous as a science is a basic requirement for examining the current model of public policies. This assay therefore uses the historiographical methodology of the Annales and the archaeological method of Foucault to historicize and investigate the formation of public policies. The ultimate goals will be to weave the extent to which public policies as a science have gained independence from this space where their ideas have come to fruition; to identify ruptures and continuities; to perceive the consequences of the rhetoric and the behaviorist theory coming from this crucible. This is the debate that this essay raises. However, it is considered, at the end, that to deny this can be an avoiding potency as it uncovers impertinent submissions that require the illusion of maintaining hegemonies and homogeneity in an idea of science.

Keywords: Public policy; behaviorism; science; policy analysis. 
Este artigo constitui-se como uma tentativa de identificar as políticas públicas em uma etapa anterior ao enfoque científico de gerenciadora da Administração Pública e seus recursos. O objetivo é investigar uma gênese dessa ideia que se denomina como ciência das políticas públicas. A justificativa para uma pesquisa nesta ótica é pelo fato de geralmente se iniciar os estudos das políticas públicas relacionando a dinâmica da formulação e da operacionalização de todo ferramental das políticas públicas com a associação a segmentos sociais, problemas jurídicos, recursos públicos, funcionalidades administrativas e daí por diante (BONETI, 2011). Pretende-se ter outro foco analisando a complexidade que antecede e que justifica a emergência de uma ideia de ciência.

A pesquisa, no entanto, percebeu como este tema é carente de produção científica. Uma busca nos principais periódicos on-line comprovará a escassez. A significativa ausência de perspectivas críticas para a análise de políticas públicas revela que a public policy possui hegemonicamente perspectivas tecnicistas e econômicas (BONETI, 2011). A que se deve isso? A pesquisa recua aos primeiros sessentas anos do século XX dos EUA, tendo em vista que as políticas públicas emergem como ciência e como forma de saber nesta circunscrição geográfica. É nesse país que surge o movimento behaviorista que revolucionou metodologicamente a forma de abordar diversas ciências, dentre elas as políticas públicas.

Por causa do behaviorismo o estudo político das políticas públicas significa dar conta do estudo do comportamento humano político de forma prática e útil à sociedade. O grupo de cientistas sociais que empreitam construir a nova disciplina política molda a identidade teórica das políticas públicas sob a forma das ciências naturais. O positivismo lógico que foi catapultado para dentro do movimento behaviorista segue para as políticas públicas (EASTON, 1953). O resultado imediato desta conexão é o almejo de encontrar as leis e as regras que regulem os comportamentos dos governos e das suas relações com os cidadãos (LASSWELL, 1936). Procura-se apartar toda espécie de interesses ideológicos, ou seja, acredita-se que possa haver neutralidade e desvinculação dos valores de ideal da política. Partindo deste pressuposto positivista, as políticas públicas procuram analisar sistematicamente os padrões dos ciclos das políticas públicas e isto significará o distanciamento entre a análise de políticas públicas e a análise filosófica e histórica política (LASSWELL, 1936).

Como já expressado o movimento behaviorista se utiliza das ferramentas do positivismo e sua abordagem se expande e se consolida nos EUA, essencialmente após a segunda guerra mundial, para o restante da Europa e da América do Sul (FERES JR., 2000). Neste artigo, a preocupação é inserir o leitor no ambiente cultural dos anos de 1910 a 1960 dos EUA, período de gênese do behaviorismo e de sua influência na ciência das políticas públicas. Ao abordar a cultura behaviorista em que as políticas públicas encontravam-se inserida, pretende-se tecer ao final uma avaliação se esta influencia permanece ou se deu apenas naquele período.

\section{AS CONDIÇÕES E AS SITUAÇÕES PARA UMA GÊNESE DAS POLÍTICAS PÚBLICAS}

As políticas públicas, em sua gênese ${ }^{1}$, advêm do movimento behaviorista norte-americano. No princípio do século XX o behaviorismo fundamenta os princípios teóricos para a emergência

1 Por gênese entenda-se uma ferramenta de trabalho investigatório. Trata-se de uma categoria de análise histórica com discursos, para desvelamento das formas de exercício do poder em saberes localizado em contextos sociais e culturais determinados. Foi largamente utilizado por Nietzsche e Foucault (MARCONDES, 2013). 
das políticas públicas. Há consenso atualmente entre historiadores políticos e cientistas sociais que, sem o advento do behaviorismo nos EUA como teoria filosófica, as políticas públicas não alcançariam a emergência que tiveram nas décadas entre 1910 a 1960 (GUNNEL, 1968; DAHL, 1961; ARON, 2002; BAUM, 2007).

Conforme Lasswell (1936), os estudos de política behavioristas nos EUA tiveram início oficialmente em 1906, quando foi criada a Organização Nacional de Ciência Política dos EUA. Os membros originais foram recrutados nas faculdades, departamentos do Governo e de grupos de destaque em estudos de Ciência Política. O objetivo, desde o princípio, foi “ultrapassar os limites descritivos para concentrar a atenção na administração pública, partidos políticos e personalidades políticas" (LASSWELL, 1936, p. 25). E David Easton complementa, quando escreve sobre qual seria a natureza dos princípios e objetivos para a definição da teoria do comportamento político (political behavior) e sobre as bases intelectuais deste movimento, que deveriam se ater a uma lista com os seguintes pontos:

Regularidades: uniformidades perceptíveis no comportamento político; 2) verificação: generalizações testadas em relação a um comportamento relevante; 3) técnicas: instrumentos rigorosos de observação; 4) quantificação: precisão na coleta de dados; 5) valores: separação da exploração empírica da avaliação de valores, sem confusão um do outro; 6) sistematização: interligação de um corpo de conhecimentos coerente e ordenado; 7) ciência pura: a compreensão e a explanação do comportamento político precedem logicamente e fornecem a base para esforço de utilizar o conhecimento político na resolução dos problemas políticos da sociedade; 8) integração: inter-relação entre as ciências para a validade da generalidade de seus resultados. Esta lista inclui, provavelmente, todos os princípios básicos da teoria do conhecimento e representa as principais diferenças entre essa abordagem e a tradicional. (EASTON, 1968. p. 26-28).

Desta forma, entre 1906, ano da fundação da Organização Nacional de Ciência Política nos EUA, até 1950, os estudos de political behavior ganham espaço e destaque. Estudos comportamentais sobre voto, eleições, personalidades políticas, vão delineando a ciência das políticas públicas. Neste período, duas obras destacam-se como marcos referenciais importantes, e podem ser identificadas como ponto de partida para o debate behaviorista: o livro do jornalista Frank Kent, Political Behavior: the heretofore unwritter, and principles of politics as practised in the United States (Política Comportamental: leis, costumes e princípios até agora não escritos das políticas e práticas nos EUA), e a obra de Herbert Tingster, Political Behavior: studies in election statistics (Política Comportamental: estudos em estatísticas eleitorais) (DAHL, 1961)².

Outro ponto importante na elaboração da ciência política voltada à objetividade, à praticidade e que leva em consideração o comportamento entre os governos e os cidadãos, é a efervescência que esta busca nos EUA provoca no restante do mundo acadêmico. Essencialmente, motivada pela primeira guerra mundial, no entre guerras (1918-1939). Diversos professores universitários e intelectuais do continente europeu migram para os EUA. Essa efervescência

2 Estas duas obras marcam a emergência das políticas públicas pelo fato essencial das terminologias utilizadas. Political behavior (teoria do comportamento político), political studies (estudos dos ciclos das políticas públicas), behavior studies (estudos comportamentais), são expressões que já percorriam as academias norte-americanas e alguns artigos já esporadicamente as citavam. Mas dentre os primeiros livros que surgem com este título específico, e que faziam uma revisão do que já se havia escrito e estudado sobre o assunto, estão a obra de Frank Kent, dos EUA, em 1928, e a de Tingsten, da Suécia, em 1937. A obra de Kent universaliza o termo political behavior nos EUA, e a obra de Tingsten trata sobre avaliação de comportamentos eleitorais na Europa, que é amplamente aceito e estudado pelos teóricos do movimento behaviorista nos EUA (FERES JUNIOR, 2000).

DE Oliveira, E.C. 
ganha dinamismo pelo fato de os EUA estarem em um continente distante do local da guerra. $\mathrm{O}$ campo de estudos se desenvolve na medida em que encontra um espaço para propor novas formas político-econômicas de desenvolvimento (HOWLETT; RAMESH \& PERL, 2013). Na Europa, entre os que migraram para os EUA, já há cientistas políticos com a tendência para a abordagem política que incorporasse os estudos da psicologia comportamental. Como afirma Gabriel Almond:

Antes da II Guerra Mundial, problemas surgidos das rápidas mudanças sociais e políticas ocorridas nos Estados Unidos determinaram uma ênfase no estudo da cena doméstica e atraíram vários pesquisadores de fora dos EUA aventurosos a experimentar métodos e estudos das relações entre estrutura social e processo, formação de personalidade, comportamento e processo político. (...) Essa fé otimista na inevitabilidade da democracia continuou durante o período entre as duas guerras mundiais, quando até mesmo o comunismo e o fascismo eram vistos como desordens temporárias ou doenças políticas. (ALMOND, 1966, p. 10).

E segundo Easton:

Os cientistas sociais passaram a encarar a integração das disciplinas em vários níveis diferentes. No nível de aplicação poderiam reunir os dados das ciências sociais como um todo para a solução de problemas globais. A unificação no entanto deveria ser feita para a prática. (...) A ideia chave desta abordagem era a convicção de que existem certas unidades básicas de análise para o comportamento humano a partir das quais podem ser feitas generalizações e essas generalizações podem fornecer uma base comum sobre a qual poderiam ser desenvolvidas as ciências especializadas do homem em sociedade. (...) Podemos concretizar o significado desta conviçção se examinarmos o caminho que se percorreu até o momento atual. Por exemplo, no caso de Talcott Parsons, a noção weberiana de ação parece ter fornecido a unidade frutífera que poderia permitir uma macroteoria comum, e com possibilidades de ser útil a todas as disciplinas sociais. Existem outras unidades de análise que já foram propostas pela Psicologia Social, entre alternativas que pareceu ser unidades promissoras. (...) Certamente bem antes da I Guerra Mundial, mas, mais especificamente desde a II Guerra Mundial tem sido feitas várias importantes adições e estas ajudariam a ampliar o âmbito da opção, a ligar a ciência política as principais correntes de pesquisa em outras disciplinas e a enriquecer seus insights teóricos. Karl Deutsch, advindo de Praga, república Checa, organizou uma estrutura conceitual particularmente elaborada para a análise comparativa e pesquisa (...) Lasswell reuniu praticamente sozinho estas perspectivas pela tentativa de integrar a teoria as pesquisas teórica e empíricas. No fim da II Guerra Mundial Herbert Simon juntou-se a ele e teve importância fundamental no despertar do ambiente científico. Simultaneamente, pesquisas em torno do voto, sob o estímulo da psicologia Social, descobriram no conceito de decisão sua matriz teórica. Embora esta lista possa não ser exaustiva, ilustra a atenção crescente que vem sendo dada em pesquisa política aos conceitos empiricamente orientados ou dentro da orientação da teoria do comportamento. (EASTON, 1968, p.36-38;42-43;45).

Desta forma, os EUA se tornarão o ambiente em cuja junção de ideias e concepções vindas da Europa vão se encontrando para a construção desta nova ciência política com viés comportamental e aplicado a soluções das práticas público-administrativas. 


\section{A INFLUENNCIA DA CULTURA BEHAVIORISTA NAS POLÍTICAS PÚBLICAS}

Neste mesmo período, Baum (2007) destaca que o movimento behaviorista norte-americano busca por uma ciência do comportamento. O movimento inicia com alguns psicólogos pelo fato de até 1940 as Universidades nos EUA atrelarem a psicologia a departamentos de filosofia. Os estudos psicológicos dentro destes departamentos estavam ligados à tradição filosófica dos estudos da interioridade e da consciência humana. O ponto de partida eram as obras trágicas gregas, em filósofos como Sêneca, Epicteto, Platão, Agostinho, Condillac, Montaigne, dentre outros pensadores da introspecção humana (BRAUSTEIN; PEWZNER, 2003). Apesar de a psicologia ter terminologias e objeto científico próprios, desde Christian Wolff e Charles Bonnet no século XVIII, a caracterização como uma ciência da consciência era unânime (BRAUSTEIN; PEWZNER, 2003). Ainda, no século XVIII, filósofos como Rousseau, Fichte, Leibniz, Schelling, e o psiquiatra Christian Heinroth inserem a ideia de inconsciente como o "estudo dos fenômenos imperceptíveis ao ser humano” (BRAUSTEIN; PEWZNER, 2003, p. 50), mas sensíveis ao conhecimento, por meio dos sonhos, da observação dos comportamentos histéricos e na própria história da humanidade. A linha dos estudos no inconsciente foi seguida por teóricos que desenvolveram célebres sistemas filosóficos, como fator subtendido na história, como fez Hegel, Karl Marx, Frederich Engels e Schopenhauer. Este último, Schopenhauer, influenciou diretamente um afamado teórico da tradição do inconsciente, Sigmund Freud (BRAUSTEIN; PEWZNER, 2003). Assim, no começo do século XX, a tradição filosófica dos estudos consciência/inconsciência, essencialmente nos EUA, sofre uma ruptura. John B. Watson, em 1913, afirma que os psicólogos haviam se emaranhado em esforços infrutíferos, ao definir a psicologia como ciência da consciência, o que somente resultou em “métodos não confiáveis e especulações infundadas", levando a questionamentos da psicologia como ciência (BAUM, 2007, p. 24). Watson propunha uma aproximação com a metodologia científica naturalista ${ }^{3}$, com um único referencial: "a observação de fenômenos naturais e mecânicos" (BAUM, 2007, p.19). Desta forma, "seguindo métodos objetivos", a psicologia poderia "romper com a filosofia e se transformar em uma verdadeira ciência” (BAUM, 2007, p. 21). Seguindo na esteira metodológica do naturalismo científico, e na contramão da tradição filosófica da consciência/ inconsciente, Watson propôs à psicologia somente:

(...) estudar o comportamento público das pessoas, ou seja, aquele que pudesse ser observado por outros, ignorando a consciência”. Construindo conceitos e termos consistentes cientificamente na descrição destes eventos (...) nada tendo a ver com revelações de uma realidade escondida além de nossa experiência (...) [pois] não há distinção entre mundos subjetivos e objetivos" (BAUM, 2007, p. 42-44).

Deste modo, por meio de Watson, torna-se manifesto o movimento behaviorista norteamericano no princípio do século XX.

De acordo com Braunstein e Pewzner (2003, p.194), Watson se forma na Universidade de Chicago, onde foi aluno de John Dewey, absorvendo seus "estudos sobre a função do psiquismo na adaptação aos ambientes numa perspectiva darwiniana”. Também se sente em Watson a influencia de "Ivan Pavlov sobre os estudos dos reflexos condicionados", além da "referencia

3 Conforme o Vocabulaire technique et critique de la philosophie, naturalismo é a "doutrina pela qual não há nada fora da natureza, no sentido dos seres que são inteiramente movidos por uma causalidade mecânica, ou, no sentido de como observamos aos objetos e aos acontecimentos tais como se apresentam ordinariamente numa sequência de fatos que temos na experiência" (LALANDE, 1988 p. 666).

de Oliveira, E.C. 
constante a Charles Darwin e Antonie Lavousier como modelo para os estudos comportamentais em psicologia" (BRAUNSTEIN; PEWZNER, 2003:195). A onda de crítica sobre Watson foi eminente, mas o modo como suas respostas às críticas se dão é que é peculiar e vale destacar. De acordo com Braunstein e Pewzner, Watson adota um:

(...) tom provocador e iconoclasta, não se contentando em publicar em revistas científicas tradicionais. Watson publica em um grande numero de obras para vulgarização de suas ideias com títulos: "Os cuidados psicológicos do bebe e da criança” (1928), publica a foto de seus filhos na capa de seus livros com o título "crianças behavioristas" e em suas entrevistas adota jargões como "dormem quando os deitam, comem o que lhes colocam a frente e não estão sujeitos ao medo nem a ira. São crianças felizes”. No entanto mais tarde um dos seus filhos se suicida e o outro durante boa parte da vida será acompanhado por um psicanalista. (BRAUNSTEIN; PEWZNER, 2003, p.194).

O que ocorre a partir da disseminação do conjunto de ideias sobre a análise comportamental no movimento behaviorista é a sua propagação como teoria filosófica da ciência. Segundo Baum, "todos os behavioristas concordam que é possível uma ciência do comportamento, que veio a ser chamada de análise comportamental” (BAUM, 2007, p.30), no entanto, mais “apropriadamente, o behaviorismo é uma filosofia dessa ciência e não uma ciência em si” (BAUM, 2007, p.18).

Como uma filosofia da ciência, os behavioristas se aproximaram de princípios teóricos fundamentais para seu método. De Pavlov e das ciências naturais, como física, química e biologia, incorporou-se a objetividade com a ênfase na mensuração (contagem dos reflexos, repetições de movimentos condicionados e incondicionados, tempo de respostas a determinadas reações). Da ideia evolutiva das espécies de Darwin, traz-se a noção de continuidade, ou seja, "a ideia de que, mesmo sendo diferentes entre si, as espécies se assemelham uma as outras, à medida que compartilham a mesma história evolutiva” (BAUM, 2007, p. 22). O psicólogo B.F. Skinner elabora experimentos com animais para comparar e conhecer os comportamentos similares entre humanos e animais. Derivado da noção de continuidade, Sappintgon (1990) e Dennet (1984) apontam o princípio da previsibilidade e do controle. Na ideia de que é possível uma ciência do comportamento, afirma Baum (2007) estar implícito que o comportamento pode ser previsto, desde que haja insumos (inputs) necessários, que se possam controlar. O próprio livre-arbítrio "é simplesmente um nome para a ignorância dos determinantes do comportamento que o regula” (BAUM, 2007, p. 28). Outro princípio metodológico importante aos behavioristas é o pragmatismo. Charles Peirce e William James, essencialmente este último, influenciam até hoje o behaviorismo. Ambos consideram que uma teoria explicativa de um conjunto de fenômenos consiste em seus efeitos práticos, ou seja, o que importa é a descrição de um fenômeno e quais reações ele implica (BAUM, 2007). A filosofia behaviorista não distingue "explicações" de "descrições", pois o que importa ao descrever comportamentos é a relação de regularidade entre um fenômeno e outro. Ao conseguir detectar relações e padrões regulares nos fenômenos humanos, afirma Baum (2007), a ciência começa. Uma vez compreensível à ordenação de determinados comportamentos tecnicamente observados, o processo de unificação constitui a própria explicação. Na década de 1970, a correspondência a este princípio foi uma teoria epistemológica encontrada em Thomas Kuhn largamente utilizada pelos teóricos em políticas públicas Gabriel Almond (1966) e David Truman (1965).

O êxito do behaviorismo na sociedade é rapidíssimo, até pela "faceta messiânica e otimista" (BRAUNSTEIN; PEWZNER, 2003, p. 203) não apenas de Watson, mas pela ousadia de teóricos 
como Skinner, que com artigos e palestras controversas discursava sobre temas como planejamento cultural e reengenharia social. Skinner propôs aos governos que poderia planejar e controlar culturas, além de ser possível reorganizar a sociedade (BAUM, 2007). Mas a provocação mais famosa vem de Watson pela frase:

Me entregue uma dúzia de crianças saudáveis e bem constituídas, a espécie de gente de que preciso para educá-las e comprometo-me, escolhendo uma ao acaso, a formá-la de maneira a fazer dela um especialista da minha preferencia, médico, comerciante, jurista ou até, mendigo ou ladrão, independente dos seus talentos, inclinações, tendências ou aptidões. (BRAUNSTEIN; PEWZNER, 2003, p. 203).

Desta forma o behaviorismo se torna uma mensagem cultural palatável e difundida a milhões de pessoas com influência incontestável. A sociedade norte-americana é inserida na behavioral revolution essencialmente pelos meios de comunicação de massa entre 1930 e 1960 (WERTHEIMER,1989; DAHL, 1961; BERKENPAS, 2012). John B. Watson, neste período, abandona a carreira universitária e vai trabalhar em uma empresa de publicidade de Nova Iorque. A ele é atribuído o início da prática do fumo de cigarro pelas mulheres nos EUA e nos países em que a propaganda de TV alcança com o slogan: "Pegue um Lucky em vez de um doce" (WERTHEIMER,1989). O potencial do behaviorismo como filosofia se faz sentir nos professores e núcleos inteiros de Universidades desenvolvendo estudos, pesquisas e trabalhos para o Governo e demais instituições através de propagandas e programas televisivos sobre comportamento em sociedade (VAN TUYLL, 1994; DAHL, 1961; BERKENPAS, 2012). Os primeiros estudos recaem sobre o comportamento militar. Mas logo instituições, grandes corporações e o próprio Governo dos EUA ampliam o pedido de estudos e pesquisas para associar a defesa da sociedade capitalista a uma propaganda de estilo de vida - the american way of life (o estilo de vida americano) (VAN TUYLL, 1994; BLANC, 1994). Em suma, a behavioral revolution se consolida nos EUA mais do que uma técnica-científica, quando seus pensadores aparecem em programas de televisão, em capas de revistas, com fotografias de "crianças behavioristas", e estuda jingles nas rádios para influenciar comportamentos, se torna um movimento estético. Da academia universitária como filosofia da ciência se inscreve entre as ideias que se relacionam a imagens, com um significado e um efeito. Ainda que advogue a objetividade como sua norma filosófica, o behaviorismo subjetivamente traz à mente um modelo, ou um estilo de sociedade, que fala mesmo quando cala sobre a cultura que ajudou a difundir na sociedade. Como diz Rancière:

É a potencia de significação inscrita em seus corpos, e que resume o "tudo fala" de Novalis, o poeta mineralogista. Tudo é rastro, vestígio ou fóssil. Toda forma sensível, desde a pedra ou a concha, é falante. Cada uma traz consigo, inscritas em estrias e volutas, as marcas de sua história e os signos de sua destinação. (RANCIÈRE, 2015, p. 35).

É significativo então expressar que a erupção das políticas públicas com a behavioral revolution in political science na sua emergência se deu pela imergência no movimento behaviorista norte-americano. E não há como deixar de relacionar a incidência dos princípios filosóficos, e da estética behaviorista, como parte da gênese das políticas públicas desde a criação da SSRC e do primeiro comitê de estudos comportamentais, com a latente preocupação de uma nova linguagem para a construção da “nova ordem”, como afirma Almond. Não houve uma evolução espontânea na ordem dos discursos das políticas públicas. Como diria Foucault (2015), o trabalho de reflexão crítica primeiramente é desalojar esses conjuntos de enunciados que articulam campos dos 
discursos como categorias universais, progressivas, lineares e evolutivas. Sobretudo quando tais posições encontram guaridas institucionais. Corre-se o risco das ordens imanentes dos enunciados se abrigarem nesta perspectiva de ensino (COSTA, 2001). O enunciado de Lasswell, por exemplo, não pode ser tomado de forma inocente, quando afirma "não é o historiador, o jurista ou o filósofo que ajudarão os cientistas políticos a resolverem seus problemas, mas os novos e crescentes grupos da moderna divisão acadêmica de trabalho" (LASSWELL, 1936, p. 26). Não parece que Lasswell está superado quando se abrem os atuais compêndios de políticas públicas e verifica-se:

(...) a formulação de Lasswell serviu de base para muitos outros modelos" [e] a orientação geral sugerida por Lasswell para atividades governamentais e para as consequências dessas ações continua conosco e constitui o assunto deste livro. (HOWLETT; RAMESH \& PERL, 2013).

Portanto, conclui-se que um estudo crítico ao conceito de políticas públicas como ciência define a compreensão sobre o papel que o estudante terá sobre a sociedade e determina a maneira como este interagirá com a própria disciplina. É apropriado afirmar que o conceito que se tem de políticas públicas define as relações que se estabelecem com o poder público organizado e com a sociedade.

\section{CONSIDERAÇÕES FINAIS}

A investigação quis apenas situar o campo histórico e conceitual do objeto, as políticas públicas. Na síntese da retrospectiva histórica, pode-se afirmar em premissa geral que o lugar comum em que as políticas públicas se localizam é no interior do movimento político behaviorista. $\mathrm{E}$ por estar ali, consolidando-se como saber científico, é que é preciso observar a relação estabelecida com o movimento behaviorista, se no seu advento foi lhe impresso algum ou alguns sentidos designando uma ou mais funções. Se no desenvolvimento desta ciência, quais são as condições que a sucessão de processos mais ou menos profundos, ou mais ou menos independentes exercem e se aplicam internamente no papel que o movimento desempenha nos princípios basilares das Políticas Públicas como ciência. Mesmo que seja para fins de defesa e reação, é preciso investigar os resultados de ações reativas que fluíram para as políticas públicas.

Em linhas gerais uma crítica consubstanciada, por conseguinte, é dizer que é razoável identificar a gênese das políticas públicas apenas com o apontamento do behaviorismo como sua célula máter. O behaviorismo está no alcance de um tempo histórico e as políticas públicas se apresentam nesta conexão, entre as representações de um tempo histórico e o triunfo de uma forma de pensar que finalmente se estabelece. A comprovação está em Lasswel que, ao efetuar uma nova distinção sobre a gestão pública, ainda carrega uma carga filosófica pesada nos estudos sem uma ruptura com os princípios do behaviorismo. Lasswell, como o fundador e ainda influenciador das políticas públicas, efetua um deslocamento na política que insere a "policy analysis" como um ingrediente behaviorista que não se modificará ao longo da história do pensamento das políticas públicas como ciência, estando presente até dias atuais (BONETTI, 2011).

Destarte o que o pesquisador precisa tentar é um ensaio sobre como essa crítica pode contribuir para as políticas públicas. Na verdade, a ideia magna é falar para dentro do público que possa tecer uma abordagem crítica das políticas públicas. Procurar achar as "sapatas" desta análise teórica fundamenta, ou seja, os pontos não móveis, as bases, que se possa destacar dentre o que o pesquisador e a crítica num diálogo metodológico possam produzir para uma atividade prática para o agente de políticas públicas. Nas palavras de Strauss e Corbim (2008, p. 165), "somente 
perguntas teóricas sobre o pensar comparativo" podem abrir a mente ao leque de possibilidades que se tentam deixar evidentes. É isto que se faz metodologicamente nesta pesquisa, fazer as mesmas perguntas, examinando olhares diferentes.

\section{REFERÊNCIAS}

ALMOND, G. Uma teoria de política comparada. Rio de Janeiro: Zahar, 1966.

ARON, R. As etapas do pensamento sociológico. São Paulo: Martin Fontes, 2002.

BAUM, W. M. Compreender o Behaviorismo. Porto Alegre: Artmed, 2007.

BERKEnPAS, J. R. The Behavioral Revolution in Contemporary Political Science: Narrative, Identity, Practice. 2016. Disponível em: <http://scholarworks.wmich.edu/dissertations/1427 2 . Acesso em: 12 jul. 2017.

BONETI, L. W. Políticas Públicas por dentro. Ijuí: Ijuí, 2011.

BRAUnSTEIN, J. F.; PEWZNER, E. História da Psicologia. Lisboa: Instituto Piaget, 2003.

DAHL, R. A. The Behavioral Approach in Political Science: Epitaph for a Monument to a Successful Protest. 1961. Disponível em: <http://www.jstor.org/stable/1952525 >. Acesso em: 20 set. 2016.

DENNET, D. C. Elboow room: the varieties of free will worth wanting. Cambridge: MIT Press, 1984.

EASTON, D. The Political System: An Inquiry into the State of Political Science. 1953. Disponível em: $<$ https://www.jstor.org/stable/2145610?seq=1\#page_scan_tab_contents $\geq$. Acesso em: 02 dez. 2016.

EASTON, D. Uma teoria de análise política. Rio de Janeiro: Zahar, 1968.

FERES Jr., J. Aprendendo com os erros dos outros: o que a história da ciência política americana tem para nos contar. 2000. Disponível em: <http://dx.doi.org/10.1590/S0104-44782000000200007 2 . Acesso em: 11 out. 2016.

GUNnelL, J. G. American Political Science, Liberalism, and the Invention of Political Theory. The American Political Science Review, Vol. 82, No. 1 (Mar., 1968), pp. 71-87.

HOWletT, M.; RAMESH, M.; PERL, A. Política Pública: seus ciclos e subsistemas: uma abordagem integral. Rio de Janeiro: Elsevier, 2013.

LALANDE, A. Vocabulaire technique et critique de la philosophie. Paris: Quadrige/PUF, 1988.

LASSWELL, H. Política: Quem ganha o que, quando, como. Brasília: UNB, 1936.

MARCONDES, D. Iniciação a História da Filosofia. Rio de Janeiro: Zahar, 2013.

RANCIÈRE, J. O inconsciente estético. São Paulo: Ed. 34, 2015.

SAPPINTGON, A. A. Recent psychological approaches to the free will versus determinismo issue. Psychological Bullettin. 1990. Disponível em: <https://my.apa.org/apa/idm/login.seam?ERIGHTS_ TARGET=http\%3A\%2F\%2Fpsycnet.apa.org\%2Ffulltext\%2F 1990-28249-001.pdf $\geq$. Acesso em: 30 maio 2017.

STRAUSS, A.; CORBIN, J. Pesquisa Qualitativa. Porto Alegre: Artmed, 2008.

TRUMAN, D. B. The Governmental Process: Political Interests and Public Opinion. New York: Alfred A. Knopf, 1951.

DE Oliveira, E.C. 
VAN TUYLL, H. P. (1994). Militarism, The United States, and The Cold War. Disponível em: $<$ https://www.scopus.com/results/citedbyresults.3b $\geq$. Acesso em: 15 jul. 2017.

WERTHEIMER, M. Pequena história da psicologia. São Paulo: Nacional, 1989. 